\title{
Alternative Methods of the Beta Coefficient Estimation
}

\author{
T. Kliestik and E. Spuchlakova
}

\begin{abstract}
This paper deals with recognizing the Market risk of an asset or portfolio of assets through the Beta Coefficient in Capital Asset Pricing Model. There is wide range of methods based on time series. One of them is Kalman filter. Kalman filter belongs to the special methodology based on correction of previous results via new observations. Kalman filter can optimally forecast the dynamic beta to measurement covariance. The aim of this paper is to show how to measure the volatility, or systematic risk, of a security or a portfolio with the Kalman filter. Kalman filter method, unlike the other estimators, imposes assumptions about the specifics functional form of beta dynamics.
\end{abstract}

Index Terms-CAPM, Beta coefficient, Kalman filter.

\section{INTRODUCTION}

Capital asset pricing model (CAPM) independently developed in 1964 by Sharpe, Lintner in 1965 and in 1966 Mossin. CAPM, the above theory of optimal portfolio. Model deals with the relationship between the average return on assets and return dispersion conditions for market equilibrium, when all investors elect optimal portfolio [1].

The starting model is the beta factor, which compares the rate of return of previous investments and rate of return of the market portfolio from a larger data set. Critics argue that the model is not testable because it is based on expected returns and the unrealistic assumptions such as:

1) Not all investors have equal access to information and equal costs of capital

2) Does not take into account taxes and transaction costs,

3) Does not take sufficiently into account the risk of illiquidity of the issuer [2].

Because of this criticism was itself modified model and its improvement and took place at the practice-stigmas. Created models such as:

1) T-CAPM model - in 1970 to create MJ Brennan and including in it the existence of taxes on capital gains and dividends, while pointing out the difference between the tax rates of income (dividends) and capital gains;

2) Zero-Beta CAPM model - which stands for the model of capital assets with zero beta factor, its author is F. Black, who claims that all available free-risk assets may not in practice always filled;

3) Consumer CAPM model - assumes that investors try to maximize their lifetime utility from consumption, its author D. Breedenem created a beta factor, which shows

Manuscript received July 5, 2016, revised September 17. This work was supported in part by the - „Kvalita a rozvoj ludských zdrojov ako piliere vedomostnej spoločnosti na Fakulte PEDAS Žilinskej univerzity v Žiline, ITMS 26110230083".

The authors are with University of Žilina, The Faculty of Operation and Economics of Transport and Communications, Department of Economics, Univerzitná 1, 01026 Žilina, Slovak Republic (e-mail: tomas.kliestik@fpedas.uniza.sk, erika.spuchlakova@fpedas.uniza.sk). the sensitivity of the instrument to change consumption investor.

4) IP-CAPM model - one of the factors that Sharpe original model was not taken into account liquidity, which significantly affects the rate of return and CE-nu instrumental, IP-CAPM model is a modification that works with liquidity as a separate factor [3].

The starting point of the CAPM, the distribution of the overall risk:

1) Unique risk - arises from the Issuer investment instruments and may be at an appropriate asset allocation very efficient diversified, so sometimes called diversified risk

2) Systematic risk - issuers of investment instruments cannot control it, because it results from the overall economic development of the individual and of macroenomic factors, also known as non-diversification if an investor invests only in domestic investment instruments [4].

\section{BETA COEFFICIENT}

As we mentioned above, the content of the CAPM is the systematic (market) risk, which we calculated using the so-called beta coefficient. From a mathematical point of view is the beta coefficient slope of a line that we can calculate methods at least-as-Squares:

$$
\beta_{i}=\frac{n \sum V_{i} V_{t}-\sum V_{i} \sum V_{t}}{n \sum\left(V_{t}\right)^{2}-\left(\sum V_{t}\right)^{2}}
$$

Beta coefficient is a standardized rate of risk assets reflected to the risk of the market, i.e. the level of systematic risk. It represents a rate of risk of securities in financial practice. If we modify the basic form of the CAPM:

$$
r_{i}-r_{f}=\beta_{i}\left(r_{M}-r_{f}\right), i=1,2, \ldots, n
$$

Then we see that a unit change of the average rate of market portfolio return leads to a greater change of the average potential return of security. It is evident that the greater the coefficient $\beta \mathrm{i}$ of the security, the more volatile the asset, i.e. unstable. Risk factor $\beta$ i therefore expresses the sensitivity of return of analysed financial asset to the market index change. ${ }^{1}$ In general, there are five options that can happen when analysing securities and they are described in the following table and graphically expressed in the following figure.

We distinguish two forms of beta coefficient:

1) ex post - beta determined by past, historical data,

2) ex ante - the estimation of beta coefficient to the future, i.e. expected beta [5].

${ }^{1}$ Size of the beta coefficient also depends on the type of company whose securities are traded, for example energetics usually has $\beta<1$ and in insurance $\beta>1$. 
TABLE I: BETA COEFFICIENT AS A DETERMINANT OF RELATION BETWEEN THE RETURN OF SECURITY AND MARKET

\begin{tabular}{|c|l|}
\hline BETA value & \multicolumn{1}{|c|}{ Development of individual security return } \\
\hline $\boldsymbol{\beta}<\mathbf{0}$ & $\begin{array}{l}\text { Return of security moves inversely to market return } \\
\text { (determined by market index) }\end{array}$ \\
\hline $\boldsymbol{\beta}=\mathbf{0}$ & Risk-free security \\
\hline $\mathbf{0}<\boldsymbol{\beta}<\mathbf{1}$ & $\begin{array}{l}\text { Return of security moves the same direction as market } \\
\text { return but slowlier. It is so called defensive security. }\end{array}$ \\
\hline $\boldsymbol{\beta}=\mathbf{1}$ & $\begin{array}{l}\text { Neutral security and its profitability changes as the } \\
\text { market do, i.e. security has an average systematic risk. }\end{array}$ \\
\hline $\boldsymbol{\beta}>\mathbf{1}$ & $\begin{array}{l}\text { Return of security moves the same direction as market } \\
\text { return but faster. It is so called offensive or aggressive } \\
\text { security. }\end{array}$ \\
\hline
\end{tabular}

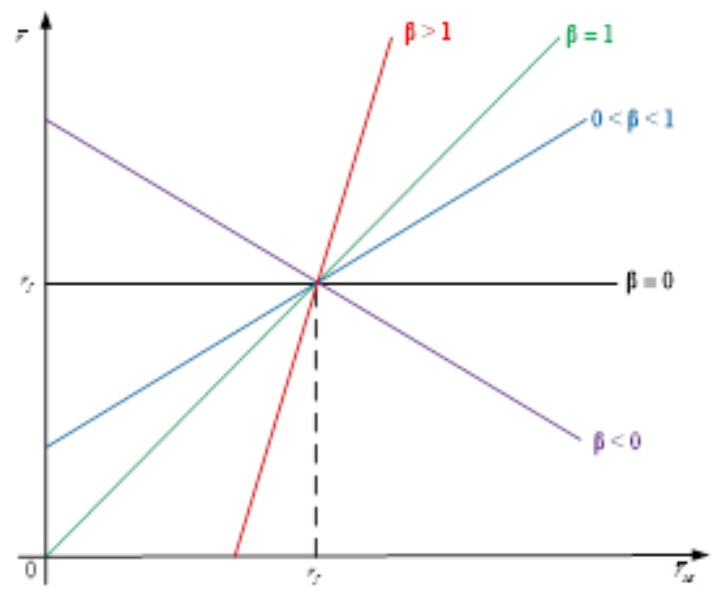

Fig. 1. Five options of Beta Coefficient development.

\section{KALMAN FILTER}

Literature shows that there have been quite a number of techniques for beta estimation. For example OLS - Ordinary Least squares, GLS - Generalized least squares, KF Kalman Filter, Adaptive KF.

The Kalman filter is over 50 years old but is one of the most important and use today. The Kalman filter framework was originally developed by Rudolf E. Kalman (1960) and became a part of the astronautically guidance system of the Apollo project. However, it has also been used for applications in other scientific fields.

Recently (and this is what we will be discussing), the Kalman filter approach has been discovered as an estimation tool in continuous time finance - only in the last decade, marked by Harvey (1989), Kalman filters have become important econometric tools for financial and economic estimation problems [6].

Using the past development of inputs and outputs, Kalman filter can estimate the states (unobserved variables) at each time point. Its algorithm consists of two steps: prediction and filtration. The steps are repeated, which means that firstly we do optimal state prediction one step forward using actually observed inputs and outputs and then the in next moment is this prediction corrected on the basis of newly observed information about measured inputs and outputs. The procedure is repeated for each time point $t$, where $t=1,2, . . \mathrm{T}$.
Firstly, the following must be said: the Kalman filter is simply an optimal recursive data processing algorithm. [7].

- To the word optimal: Because there are many ways to define "optimal", a criterion of that optimality has to be chosen. It can be shown that, under the speci_c assumption, the Kalman filter is optimal with respect to virtually any criterion that makes sense. One aspect of that optimality is that the algorithm incorporates all information it can be provided with. It processes all measurements to estimate the current value of the variables of the interest, with use of [8]:

1) knowledge of the system and measurement device dynamics,

2) the statistical description of the system noises, measurement errors, uncertainty in the dynamics models, and

3) any available information about initial conditions of the variables of interest.

- To the word recursive: unlike certain data processing concepts, the Kalman filter does not require all previous data to be kept in storage and reprocessed every time a new measurement is taken. This is very useful for the filter's practical implementation. [9].

Figure 2 depicts a typical situation in which the Kalman filter could be used: a system is driven by known controls and measuring devices provide the value of certain pertinent quantities. Knowledge of these system inputs and outputs is all that is explicitly available from the physical system for estimation purposes. [10].

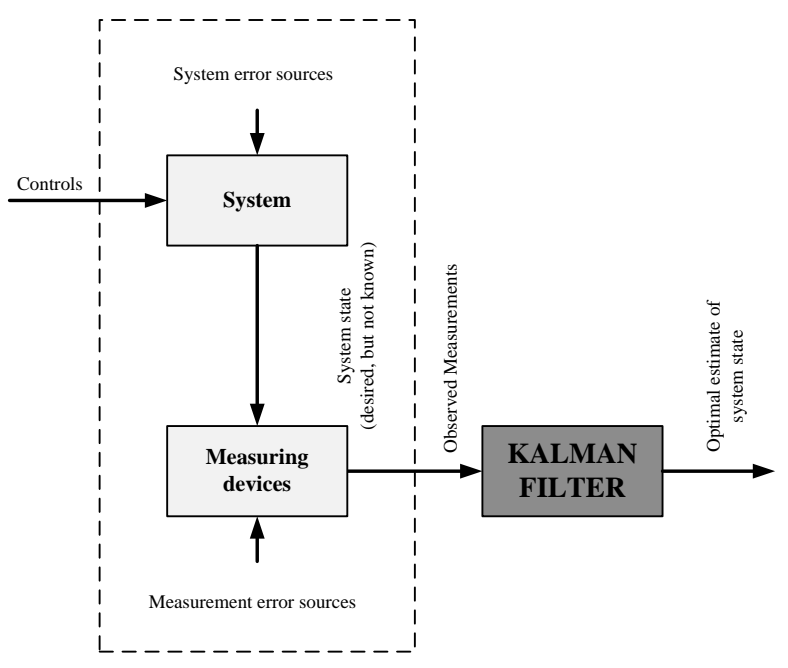

Fig. 2. Typical Kalman filter application.

The word "need" for a filter will be now explained: often the variables of interest, some finite number of parameters to describe the state of the system, cannot be measured directly some values from the available data must be generated.

The Kalman filter is based on the so-called endless cycle. Based on the known initial value, the future state is firstly estimated and after gaining new and actual information is the prediction corrected to estimate the future state as accurate as possible. After getting newer data is the prediction modified again and again and the cycle is repeated continuously. The advantage of Kalman filter is that it is not necessary to remember all the previous values. We use the equation (2), but we must modify it: 


$$
r_{i}-r_{f}=\alpha_{i}+\beta_{i}\left(r_{M}-r_{f}\right)+\varepsilon_{i}
$$

where:

$\alpha_{i}$ - measure of an incorrect valuation of securities

$\varepsilon_{i}$ - random, residual fault.

The CAPM assumes the balance on the security market, which is obviously a simplification of reality [11].In the real world security returns are determined by situation in the financial markets. ${ }^{2}$ As we use the real world data and Kalman filter we are able to detect where the $\alpha i$ differs more or less from zero, and it can help us to identify the reasons of this market development. The same principle is used for coefficient $\beta i$ volatility, which is influenced not only by the marke development (exogenous factors) but also by the development of the company which issued securities (endogenous factors). Equation (3) is modified to so-called measurement equation that describes the relation between state and measured values:

$$
R_{t}-R_{f}=X_{t} B_{t}+\varepsilon_{t}
$$

where:

$$
\begin{aligned}
& R_{t} \text { - security return, } \\
& X_{t} \text { - vector, if } X_{t}=\left(1, R_{M}-R_{f}\right), \\
& R_{f} \text { - risk-free return rate, } \\
& B_{t} \text { - vector, if } B_{t}=\left(\alpha_{t}, \beta_{t}\right)^{\mathrm{T}}, \\
& \varepsilon_{t}-\text { vector of random faults, if } \varepsilon_{t} \sim N\left(0, \sigma^{2}\right) .
\end{aligned}
$$

Next, we will need so called transition equation or transitive equation, which describes the transition from the state $B_{t-1}$ to the state $B_{t}$ :

$$
B_{t}=\Phi B_{t-1}+\omega_{t}
$$

where:

$B_{t}$ - state vector with information about system in time t,

$\phi$ - transitive matrix with fixed coefficients with $(2 \times 2)$ dimension which explains the transition from $t$-1 time to the state in time $\mathrm{t}$,

$\omega_{t}$ - independent random faults, if $\omega_{t} \sim \mathrm{N}\left(0, \sigma^{2} \Omega\right)$,

$\Omega$ - final symmetric matrix with $(2 \times 2)$ dimension.

For the mean values of $\varepsilon_{t}$ and $\omega_{t}$ must apply:

$$
\begin{aligned}
& E\left(\varepsilon_{t}, \omega_{s}^{T}\right)=0 \\
& \forall s, t=1, \ldots, T
\end{aligned}
$$

If we note the estimate of vector $B$ at the time $t$ with the condition that the relevant information is available at the time $t-1$ as $\hat{B}_{t \mid t-1}$ it is possible to quantify the error (e - error) of this estimate $B_{t \mid t-1}^{e}$ as the difference between actual vector $B_{t}$ and estimated vector $\hat{B}_{t \mid t}$ :

$$
B_{t \mid t-1}^{e}=B_{t}-\hat{B}_{t \mid t}
$$

Then the variance of this miscalculation:

$$
E\left\{B_{t \mid t-1}^{e} B_{t \mid t-1}^{e}{ }^{T}\right\} \equiv P_{t \mid t-1}
$$

When formulating Kalman filter we assume that so called

\footnotetext{
${ }^{2}$ Financial markets reflect the situation in countries, for instance economic and financial crisis, terrorism, war, crop failure, booms, etc..
}

hyper parameters of the $\operatorname{model}^{3}$ (i.e. variance $\sigma^{2}$, covariance matrix $\sigma^{2} \Omega$ and transition matrix $\Phi$ ) are known. Next, we define the following linear relation, by which we estimate the $\hat{B}_{t \mid t}$ vector based on knowledge of $\hat{B}_{t \mid t-1}$ estimation, innovation $z_{t}$ and matrix $K_{t}$ :

$$
\hat{B}_{t \mid t}=\hat{B}_{t \mid t-1}+K_{t} z_{t}
$$

where:

$K_{t}$ - matrix of Kalman gain.

Innovation $z_{t}$ (innovation) defines the difference between estimated and real state:

$$
z_{t}=\left(R_{t}-X_{t} \hat{B}_{t \mid t-1}\right)
$$

where:

$z_{t}$ - innovations, which are mutually independent and if $\mathrm{z}_{\mathrm{t}} \sim$ $\mathrm{N}\left(0, \sigma^{2} \mathrm{f}_{\mathrm{t}}\right)$,

If $z_{t}=0$, i.e. $R_{t}=X_{t} \hat{B}_{t \mid t-1}$, then the estimation of $\hat{B}_{t \mid t}$ state equals to $\hat{B}_{t \mid t-1}$ prediction.

To minimize the variance $P_{t \mid t}$ we use the matrix $K_{t}$, which we call Kalman gain. Kalman gain defines how greatly $K_{t}=P_{t \mid t-1} X_{t}^{T}\left(X_{t} P_{t \mid t-1} X_{t}^{T}+\sigma^{2} \Omega\right)^{-1}=\frac{P_{t \mid t-1} X_{t}^{T}}{X_{t} P_{t \mid t-1} X_{t}^{T}+\sigma^{2} \Omega}$ is the state $\hat{B}_{t \mid t}$ influenced by improvement and it has the following form:

$$
P_{t \mid t}=\left(I-K_{t} X_{t}\right) P_{t \mid t-1}
$$

where:

$I$ - unit matrix,

If $\lim _{\Omega_{t} \rightarrow 0} K_{t}=X^{-1}$ then the greater credibility is given to actual measures than to values obtained by predictions. Otherwise, if $\lim _{P_{t \mid t-1} \rightarrow 0} K_{t}=0$ then the greater credibility is given to predictions. By $K_{t}$ matrix is also determined estimation of $\hat{B}_{t \mid t}$ state and of variance $P_{t \mid t}$.

The algorithm for calculating the beta coefficient using Kalman filter is shown in Fig. 3. If we know4 the state $B_{0}$ and its variance $P_{0}$, then we estimate the state $\hat{B}_{1 \mid 0}$ and its variance $P_{1 \mid 0}$. After gaining new data $X_{1}$ Kalman gain $K_{1}$ is calculated and the estimation of the $\hat{B}_{1 \mid 1}$ state and its variance $P_{1 \mid 1}$ are modified. Then the whole process is repeated, i.e. we again estimate the state $\hat{B}_{2 \mid 1}$ and its

\footnotetext{
${ }^{3}$ Hyper parameters of the model are not known in advance and they must be estimated. This estimation may be done by the function of maximal credibility.

${ }^{4}$ If we do not know $B_{0}$ and $P_{0}$, which happens quite frequently, then they must be estimated on the basis of the first k observations by the LSM method.
} 
variance $P_{2 \mid 1}$ and after gaining the new data Kalman gain $K_{2}$ is calculated, etc. [12].

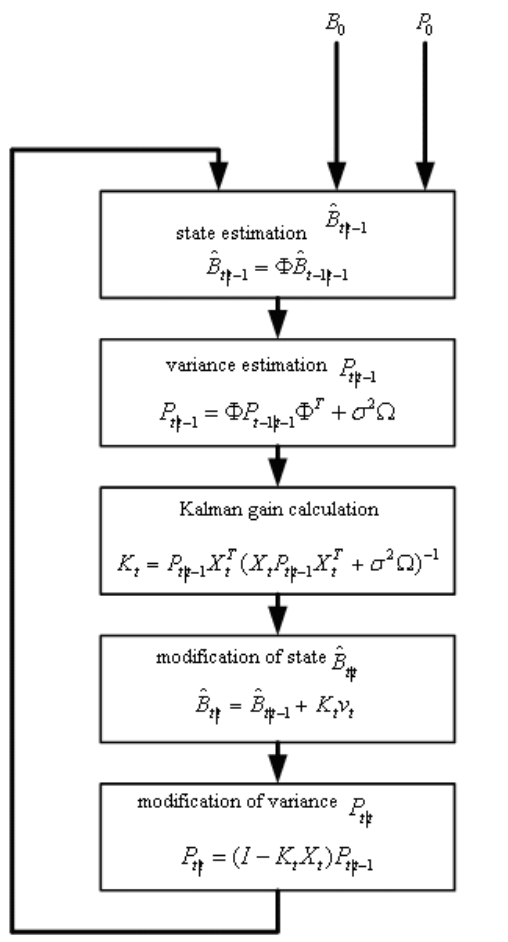

Fig. 3. Algorithm of Kalman filter.

\section{CONCLUSION}

This paper characterizes the Kalman filter for beta estimation. We can conclude that the Kalman filter is the optimal filter for a linear model subject and it can be derive by using conditional expectation. This filter is known to be able to support estimations for past, present, and also future states even when the precise nature of the modelled system is unknown. Its great advantage is based on the direct operating, i.e. to calculate the best estimate only if past estimation and new measurements are used and previous measurements are not important. Kalman filter can be applied to obtain so-called smoothed values $\hat{B}_{t \mid t}$. These state estimates based on all available data in the sample are firstly gained by the Kalman filter and by re-recursion beginning with the last filtered state $\hat{B}_{t \mid t+1}$

\section{REFERENCES}

[1] J. Campbell and T. Vuolteenaho, "Bad beta, good beta," American Economic Review, vol. 94, pp. 1249-1275, 2004.

[2] A. Ang and J. Chen, "CAPM over the long-run: 1926-2001," Journal of Empirical Finance, vol. 14, pp. 1-40, 2007.

[3] T. Klieštik and Š. Cisko. (2014). Beta coefficient and estimation by kalman. [Online]. Available: http://www.researchgate.net/publication/260767107

[4] M. Bod'a and M. Kanderová, "The capital asset pricing model overviewed," Towards Information-Based Welfare Society. Publishing House of Wroclav University of Economics: Wroclav, 2009.

[5] J. Lintner, "The valuation of risk assets and selection of risky investments in stock portfolio and capital budgets," Review of Economics and Statistics, vol. 47, pp. 13-47, 1965.

[6] R. Engle, T. Bollerslev, and J. Wooldridge, "A capital asset pricing model with time varying covariances," Journal of Political Economy, vol. 96 , pp. 116-131, 1988 .

[7] F. E. Fama and R. K. French, "The CAPM is wanted, dead or alive," Journal of Finance, vol. 51, no. 5, pp. 1947-1958, 1966.

[8] J. Mossin, "Equilibrium in a capital asset pricing market," Econometric, vol. 34, pp. 768-83, 1966.

[9] F. W. Sharpe, "Capital asset prices: A theory of market equilibrium under condition of risk," Journal of Finance, vol. 19, no. 3, pp. 425-442, 1964.

[10] M. Theobald, "Beta Stationarity and Estimation Period: Some Analytical Results," Journal of Financial and Quantitative Analysis, vol. 16, no. 5, pp. 747-757, 1981.

[11] J. Tobin, "Liquidity preference as behaviour towards risk," The Review of Economic Studies, vol. 25, no. 2, pp. 65-86, 1958.

[12] R. E. Kalman, "A new approach to linear filtering and prediction problems," Journal of Basic Engineering, ASME Transactions, Series $D$, vol. 82 , pp. $35-45,1960$

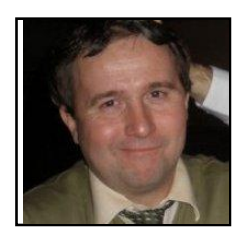

T. Klieštik was born in Čadca in 1973. He was studied at Comenius University in Bratislava. After this study, he became the professor assistance in University of Žilina, The Faculty of Operation and Economics of Transport and Communication. Now, T. Klieštik is the professor, and he is also the head of the Department of Economic. 